\title{
Relationship between renal injury and the antagonistic roles of angiotensin-converting enzyme (ACE) and ACE2
}

\author{
C. Ma, H. Xin, X.-Y. Jiang, Y.-X. Wang and Y.-S. Zhang \\ Key Laboratory of Animal Physiology and Biochemistry, \\ Ministry of Agriculture, Nanjing Agricultural University, Nanjing, China \\ Corresponding author: Z. Yuan-Shu \\ E-mail: zhangyuanshu@njau.edu.cn
}

Genet. Mol. Res. 13 (2): 2333-2342 (2014)

Received May 10, 2013

Accepted June 6, 2013

Published April 3, 2014

DOI http://dx.doi.org/10.4238/2014.April.3.5

\begin{abstract}
Angiotensin-converting enzyme 2 (ACE2), a newly discovered carboxypeptidase in the renin-angiotensin system (RAS), antagonizes ACE activity and plays an active role during tissue injury. Yet the mechanism of its action is not well known. Using a streptozotocin (STZ)-induced renal injury rat model, we investigated the relationship between renal injury and the antagonism between ACE and ACE2. We assayed the levels of urea nitrogen, urine glucose, creatinine, and protein, Ace 2, Ace, angiotensin II type 1 receptor (At1) and Mas receptor mRNA, and renal and plasma angiotensin II (Ang II) in STZ-treated and untreated rats. We also used histology and immunohistochemistry to assess glomerular injury and ACE2 glomerular and cortical expression. The amounts of urea nitrogen, urine glucose, creatinine, and protein were significantly higher in STZ-treated rats than in control rats $(\mathrm{P}<$ 0.01). There were significant pathological changes in the kidney upon STZ-treatment. Ace 2 and Ace mRNA levels were significantly higher in STZ-treated rats than in control rats $(\mathrm{P}<0.05$ and $\mathrm{P}=0.05$, respectively). There was no significant difference in the Mas receptor and At 1 mRNA levels in the 2 groups, although At1 levels showed an increase upon STZ-treatment. The Ang II level in the renal cortical tissue and plasma
\end{abstract}


of STZ-treated rats was higher than that of control rats $(\mathrm{P}<0.05)$. The increase in Ace mRNA levels was higher than that of Ace 2 mRNA levels, leading to an elevated Ace/Ace2 ratio. Together, these data suggest that the ACE-Ang II-AT1 axis is the dominant axis in severe kidney injury.

Key words: Rat; Kidney injury; ACE2; ACE; Negative regulation

\section{INTRODUCTION}

The renin-angiotensin system (RAS) is an important system in cardiovascular and kidney function, that through the classical angiotensin-converting enzyme (ACE)-angiotensin II (Ang II)-angiotensin II receptor, types 1 and 2 (AT1/AT2) pathway, regulates water and salt metabolism, maintains blood volume and vascular tone, and regulates heart and kidney function. Excessive RAS activation is known to be the one of the main reasons for cardiovascular disease, stress, myocardial injury, and end-stage kidney disease (Santos et al., 2008). Much research is focused on the regulation of the key components of RAS for the treatment of heart and kidney diseases.

ACE2 is a newly discovered member of RAS that negatively regulates this system (Donoghue et al., 2000). ACE2 hydrolyzes Ang II to form Ang-(1-7). Through the antagonistic effect of the Mas receptor on Ang II, Ang-(1-7) reduces vasoconstriction, water and salt metabolism imbalance, and other negative effects that occur in disease, and thus has a certain anti-injury effect (Koka et al., 2008; Santos et al., 2008).

Research shows that ACE2 is highly expressed in the kidney and that it hydrolyzes Ang II to Ang-(1-7) mainly in the renal proximal tubules and regulates kidney function (Donoghue et al., 2000). Ye et al. (2004) reported that although Ace mRNA and protein levels and ACE activity decrease in the renal cortex in an animal model of the early diabetic phase, Ace 2 mRNA expression does not decrease in this model; in fact, ACE2 protein expression and activity increase significantly, suggesting that ACE2 may play a renal protective role in early diabetes. By studying 24 week old rats with diabetic nephropathy, Tikellis et al. (2003) found that ACE2 protein expression decreased by $30 \%$ in the renal tubule, causing a partial increase in Ang II levels and resulting in renal tubulointerstitial fibrosis, furthermore, the ACE2 expression level in rats treated with the Ramipril drug is similar to that of non-diabetic nephropathy rats. This shows that the renal protective effects of the ACE inhibitor may be achieved via its regulation of ACE2.

These results suggest that ACE2 plays an important role in renal injury. However, the question of how ACE2 responds to an increase in Ang II levels due to ACE hydrolysis and to changes in the expression levels of the Mas and AT1 receptors needs further study. Therefore, using a streptozotocin-based rat model for renal injury and by observing the changes in the mRNA expression of Ace2, Ace, the downstream Mas receptor and At1, and measuring Ang II content in circulating blood and renal tissue, we aimed to better understand the role and mechanism of action of ACE and ACE2 in renal injury.

\section{MATERIAL AND METHODS}

\section{Main reagents}

The Ang II radioimmunoassay kit was purchased from Beijing Northern Biotechnology 
Institute (China). The Strept Avidin-Biotin Complex (SABC) immunohistochemistry kit was purchased from Boshide Wuhan Biological Engineering Co. Ltd (China). The glucose assay kit, blood urea nitrogen kit, urine creatinine assay kit, and protein assay kit were purchased from Nanjing Jiancheng Bioengineering Institute (China). Streptozotocin (STZ) was purchased from Sigma Corporation (USA).

Taq polymerase enzyme was purchased from Bao Biotechnology Co. Ltd (China). Polymerase chain reaction (PCR) primers were synthesized by the Life Technologies Corporation (USA). TRIzol Plus was purchased from Nanjing TianWei Biotechnology Co. Ltd (China).

\section{STZ-diabetic rats}

Twenty healthy adult male Sprague-Dawley (SD) rats [Experimental Animal Center of Southeast University, China; SYXK (Su) 2001-0017] weighing 200-220 g were randomly assigned to the control group and experimental group. The experimental group was administered STZ intraperitoneally ( $60 \mathrm{mg} / \mathrm{kg}$ body weight). The rats were fasted for $8 \mathrm{~h}$ and fasting blood glucose was measured at $24 \mathrm{~h}$ and $72 \mathrm{~h}$. Rats with fasting blood glucose levels at least twice as high as $16.7 \mathrm{mM}$ were considered to be renal tissue injury rat models. After 30 days, 8 rats randomly from every group were killed, and plasma, urine, and kidneys were collected immediately.

\section{Biochemical testing}

Physiological parameters were measured as follows: urine glucose $(\mathrm{mM})=[$ optical density (OD) determination/OD standard] x standard control concentration (5.55 mM); urine creatinine $(\mu \mathrm{M})=[(\mathrm{OD}$ determination - OD Blank $) /(\mathrm{OD}$ standard - OD Blank $)] \mathrm{x}$ standard control concentration $(10 \mu \mathrm{M}) \times 201$; urea nitrogen $=[(\mathrm{OD}$ determination - OD blank $) /(\mathrm{OD}$ standard - OD blank)] x standard control concentration $(10 \mathrm{mM})$. Urine protein was measured by the Bradford assay.

\section{Histopathology}

Rat kidney tissues were fixed, dehydration, hyalinized, waxed, sliced routinely to $5-\mu \mathrm{m}$ serial sections, and stained with hematoxylin and eosin (H\&E) stain. Sections with imaged with an optical microscope.

\section{RNA isolation and reverse transcriptase PCR (RT-PCR)}

Total RNA was extracted from the kidney tissue of rats using the TRIzol kit (Invitrogen, Carlsbad, CA, USA) according to manufacturer protocol. Single-stranded cDNA was synthesized by a reverse-transcriptase reaction with random primers and M-MLV reverse transcriptase (SunShine Bio, China). The resulting cDNA was assayed for Ace2, Ace, angiotensin II type 1 receptor $(A t 1)$ and Mas receptor mRNA expression. The mRNA levels of target genes were normalized to $\beta$-actin mRNA levels (Table 1). Target gene and $\beta$-actin primers were designed based on their GenBank sequence using the Primer 5.0 software (Invitrogen, USA). Each sample was run and analyzed in duplicate. The intensity of the bands corresponding to PCR products was measured by densitometry. 
Table 1. Parameters of primer pairs for ACE, AT1, ACE, Mas, and $\beta$-actin genes.

\begin{tabular}{|c|c|c|c|c|}
\hline Gene & GenBank accession No. & Primers sequence $\left(5^{\prime}-3^{\prime}\right)$ & Orientation & Product size (bp) \\
\hline ACE & NM012544 & $\begin{array}{l}\text { 5'-ATGCCTCTGCGTGGGACTTC-3' } \\
\text { 5'-TACTGCACGTGGCCCATCTC -3' }\end{array}$ & $\begin{array}{l}\text { Forward } \\
\text { Reverse }\end{array}$ & 112 \\
\hline AT1 & NM030985 & $\begin{array}{l}\text { 5'-CCCACTCAAGCCTGTCTACGAA-3' } \\
\text { 5'-GTGTGCTTTGAACCTGTCACTCC-3' }\end{array}$ & $\begin{array}{l}\text { Forward } \\
\text { Reverse }\end{array}$ & 120 \\
\hline ACE2 & AY881244 & $\begin{array}{l}\text { 5'-AATCGTAGGCTCTGGGCTTGG-3' } \\
\text { 5'-TTCGATCAACTGGTTTCGGTTGTA-3' }\end{array}$ & $\begin{array}{l}\text { Forward } \\
\text { Reverse }\end{array}$ & 182 \\
\hline Mas & NM012757 & $\begin{array}{l}\text { 5'-TGACAGCCATCAGTGTGGAGA-3' } \\
\text { 5'-GCATGAAAGTGCCCACAGGA-3' }\end{array}$ & $\begin{array}{l}\text { Forward } \\
\text { Reverse }\end{array}$ & 116 \\
\hline$\beta$-actin & AF122902 & $\begin{array}{l}\text { 5'-CCCTGTGCTGCTCACCGA-3' } \\
\text { 5'-ACAGTGTGGGTGACCCCGTC-3' }\end{array}$ & $\begin{array}{l}\text { Forward } \\
\text { Reverse }\end{array}$ & 198 \\
\hline
\end{tabular}

\section{Plasma and renal tissue Ang II levels}

The concentrations of Ang II in plasma and renal cortex were measured by radioimmunoassay using the RIA kit according to manufacturer protocol. Samples, standards, and controls were incubated with [ $\left.{ }^{125} \mathrm{I}\right]$-Ang II and rabbit anti-Ang II antibody for $18 \mathrm{~h}$. To separate bound radioactive Ang II from unbound ligand, a separating medium was added to the mixture for $20 \mathrm{~min}$ and the precipitated bound fraction was separated by centrifugation and counted in a $\gamma$-counter.

\section{Immunohistochemistry}

ACE2 was detected by immunohistochemistry using the SABC kit following manufacturer protocol. Paraffin-embedded sections $(5 \mu \mathrm{m})$ were baked at $65^{\circ} \mathrm{C}$, dewaxed, and hydrated. They were treated with $3 \% \mathrm{H}_{2} \mathrm{O}_{2}$ to block endogenous peroxide and the antigen was exposed by treatment with boiling citrate buffer $(0.01 \mathrm{M}, \mathrm{pH}$ 6.0). Sections were blocked with 5\% BSA. A goat anti-ACE2 polyclonal antibody (Santa Cruz Biotechnology, Santa Cruz, CA, USA) was used at a dilution of 1:50 and was incubated overnight at $4^{\circ} \mathrm{C}$. The antibody was detected by the SABC method according to manufacturer protocol for the SABC kit. Color was developed using the DAB substrate and the slides were mounted. For negative controls without the primary antibody, only the antibody dilution buffer was applied.

\section{Statistical analysis}

Statistical analyses were performed using the SPSS 16.0 software (SPSS, Chicago, USA). Comparison of mean values between multiple groups was analyzed by the $t$-test and the one-way analysis of variance. Measurement data are reported as means $\pm \mathrm{SD}$.

\section{RESULTS}

\section{Weight and feeding and drinking habits of the control and STZ-treated rats}

The results are shown in Table 2. The control group gained relative weight significantly, were in good health, and showed movement and mobility responsive. In contrast, the STZtreated group rats were inactive, showed sluggish movements, skin dryness, and increased water and food intake. 
Table 2. Change of relative weight, hydroposia and cibation in rats $(\mathrm{N}=8)$.

\begin{tabular}{lccc}
\hline Group & Relative weight $(\mathrm{g})$ & Hydroposia $(\mathrm{mL})$ & Cibation $(\mathrm{g})$ \\
\hline Control group & $74.15 \pm 3.33$ & $40.43 \pm 1.21$ & $28.50 \pm 2.34$ \\
STZ group & $21.09 \pm 2.62$ & $233.22 \pm 8.72$ & $47.43 \pm 2.11$ \\
\hline
\end{tabular}

\section{Blood glucose and biochemical parameters of urine in rats}

The results are shown in Table 3. The amounts of urine glucose, urea nitrogen, urine creatinine, and urine protein in STZ-treated rats were significantly higher than those in the control group $(\mathrm{P}<0.01)$

Table 3. Blood glucose and parameters of urine in rats $(\mathrm{N}=8)$.
\begin{tabular}{lccccc}
\hline Group & $\begin{array}{c}\text { Fasting blood } \\
\text { glucose }(\mathrm{mM})\end{array}$ & $\begin{array}{c}\text { Urine protein } \\
(\mathrm{mg} / \mathrm{L})\end{array}$ & $\begin{array}{c}\text { Urine glucose } \\
(\mathrm{mM})\end{array}$ & $\begin{array}{c}\text { Urine creatinine } \\
(\mathrm{mM})\end{array}$ & $\begin{array}{c}\text { Urine nitrogen } \\
(\mathrm{mM})\end{array}$ \\
\hline Control group & $5.75 \pm 0.27$ & $27.9 \pm 4.1$ & 0 & $3.02 \pm 0.39$ & $258.94 \pm 23.94$ \\
STZ group & $25.99 \pm 0.60^{* *}$ & $333.5 \pm 89.3^{* *}$ & $9.47 \pm 0.71^{* *}$ & $15.41 \pm 1.10^{* *}$ & $313.35 \pm 31.40^{* *}$ \\
\hline
\end{tabular}

**Differences between groups with $\mathrm{P} \leq 0.01$.

\section{Histopathology}

As can be seen from the results of the H\&E staining (Figure 1), STZ-treated rats showed glomerulosclerosis, diffuse mesangial broadening (Figure 1C), and a thicker arterial endothelium compared to the control group. Renal damage included full of spots (Figure 1B) and the shedding of renal tubular epithelial cells at the sites of severe lesions (Figure 1D).
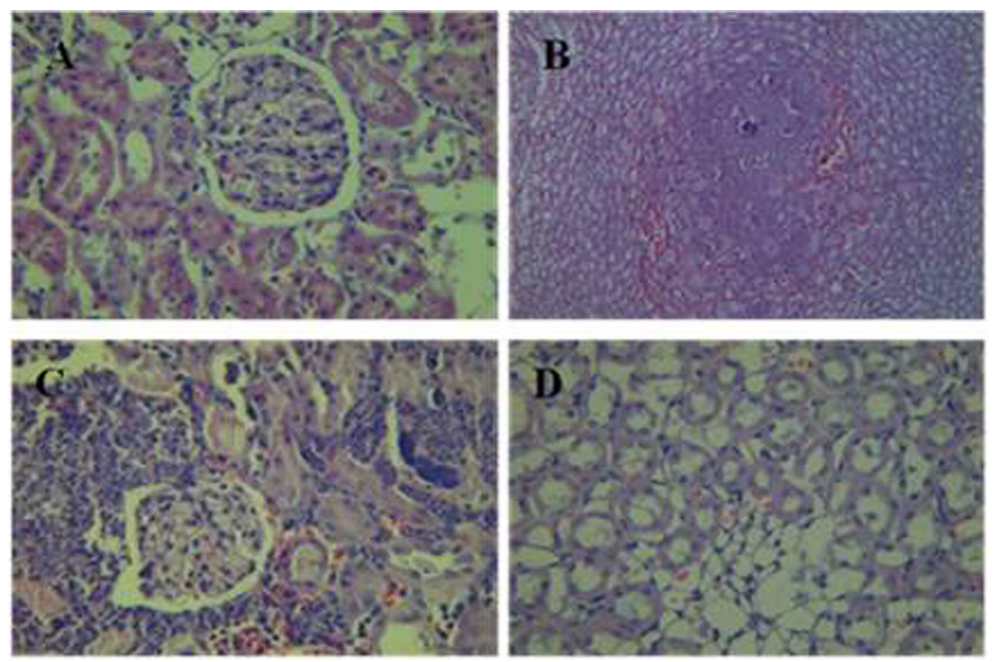

Figure 1. Tissue structure of kidney by HE. Sections from Experiment group rats, C, D is 400X, B is 100X; Section from Control group, A is 400X. 


\section{Semiquantitative analysis of renal $A c e 2, A c e, A t 1$, and Mas receptor mRNA}

The results of the semiquantitative analysis of renal Ace2, Ace, At1, and Mas receptor mRNA are shown in Figures 2 and 3. As can be seen from Figure 2, the level of Ace2 mRNA in renal tissue was significantly higher in the renal injury rat model than in the control rats $(1.2134 \pm 0.0883$ vs $1.4708 \pm 0.0276, \mathrm{P}=0.028)$. Ace mRNA levels also were also significantly higher in STZ-treated rats than in the control group $(1.14 \pm 0.05 v s 1.45 \pm 0.04, \mathrm{P}=$ 0.05). Although At1 mRNA expression was slightly higher in STZ-treated rats as compared to control rats, this difference was not statistically significant $(0.8866 \pm 0.0732$ vs $0.9160 \pm$ $0.0506, \mathrm{P}=0.25)$. Mas receptor mRNA levels were not significantly different between the 2 groups $(1.0323 \pm 0.2173$ vs $0.9627 \pm 0.1180, \mathrm{P}=0.17)$.

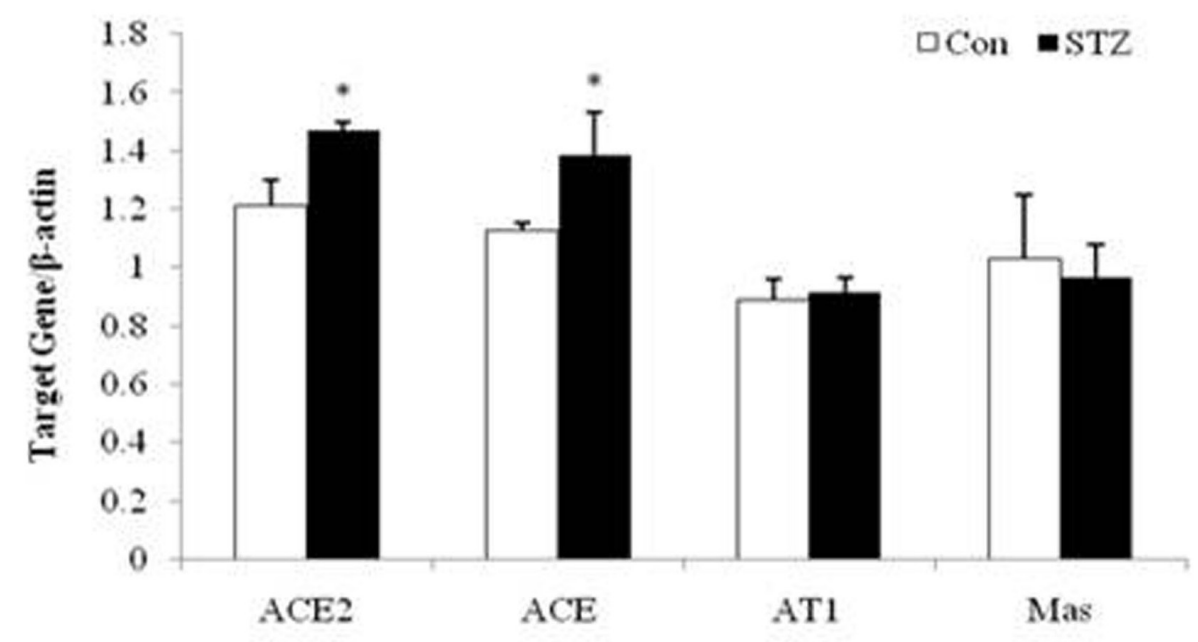

Figure 2. Expression of ACE2, ACE, AT1, Mas mRNA in rat kidneys $(\mathrm{N}=8)$.

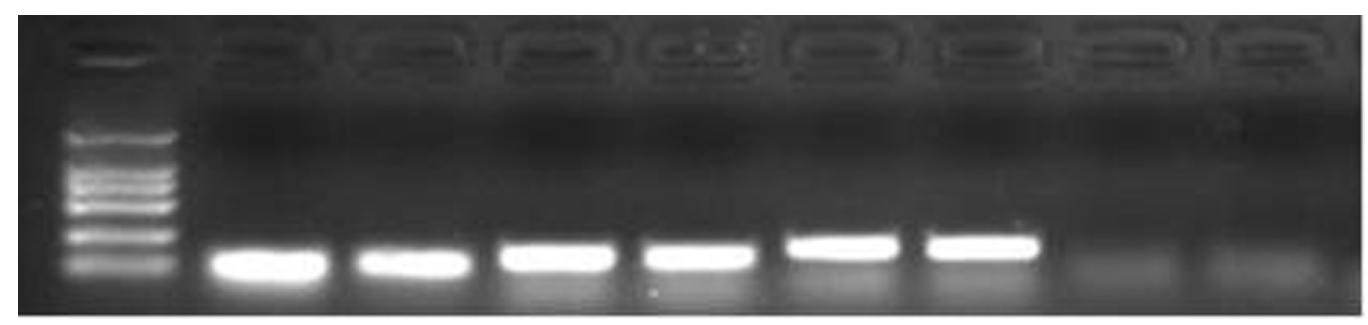

Figure 3. Result of ACE, ACE2, and $\beta$-actin PCR. DNA Marker; lanes 2, $3=\mathrm{ACE}$; lanes 4, $5=\mathrm{ACE} 2$; lanes $6,7=\beta$-actin; lanes $8,9=\mathrm{H}_{2} \mathrm{O}$ control.

\section{Ace/Ace 2 mRNA ratio in renal tissue}

The results are shown in Table 4. Ace/Ace 2 mRNA ratio was significantly higher in STZ-treated rats than in normal controls. 
Table 4. ACE/ACE2 mRNA expression ratio in rat kidneys $(\mathrm{N}=8)$.

\begin{tabular}{lcc}
\hline & Control group & STZ group \\
\hline ACE/ACE2 & 0.926 & 0.941 \\
\hline
\end{tabular}

\section{Ang II levels in plasma and kidney tissue}

The results are shown in Figures 4 and 5. STZ-treated rats showed significantly higher Ang II concentrations in both plasma $(1.57 \pm 0.33$ vs $3.00 \pm 0.58, \mathrm{P}<0.05)$ and kidney tissue $(0.868 \pm 0.078 v s 1.122 \pm 0.038, \mathrm{P}<0.05)$ when compared with normal control rats.

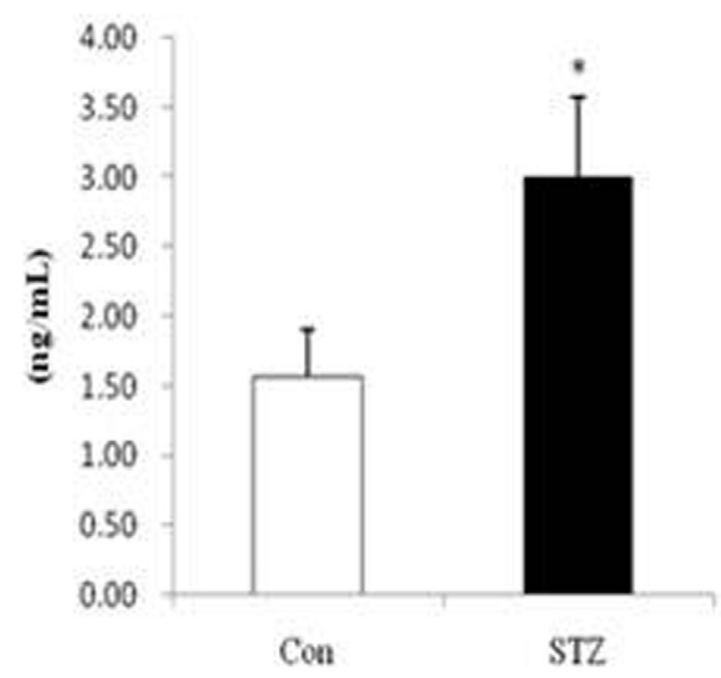

Figure 4. Content of AngII in plasma $(\mathrm{N}=8)$.

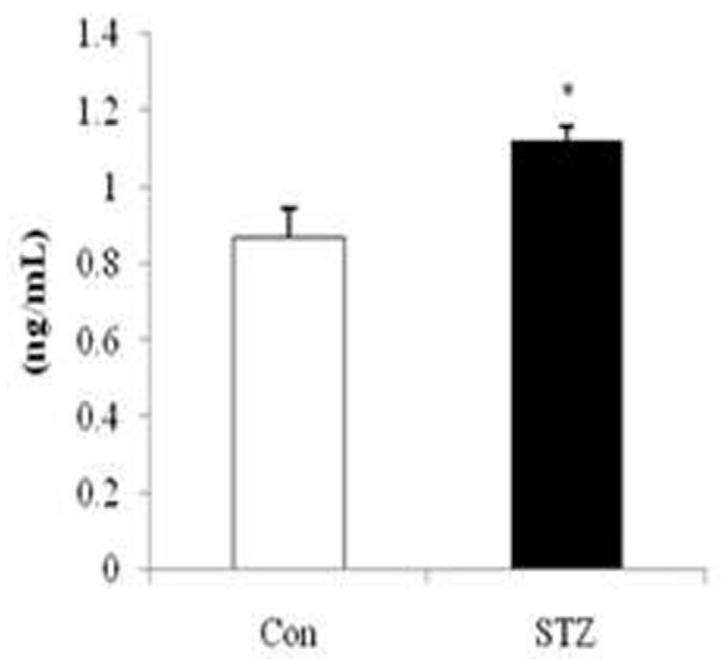

Figure 5. Content of AngII in kidney $(\mathrm{N}=8)$. 


\section{Immunohistochemistry}

The results from the immunohistochemistry experiments are shown in Figure 6. ACE2 protein, stained in brown and tan, was mainly located in the cell membrane of renal tubular epithelial cells. The ACE2 protein was expressed more broadly in the renal tubules of STZtreated rats than in control rats.
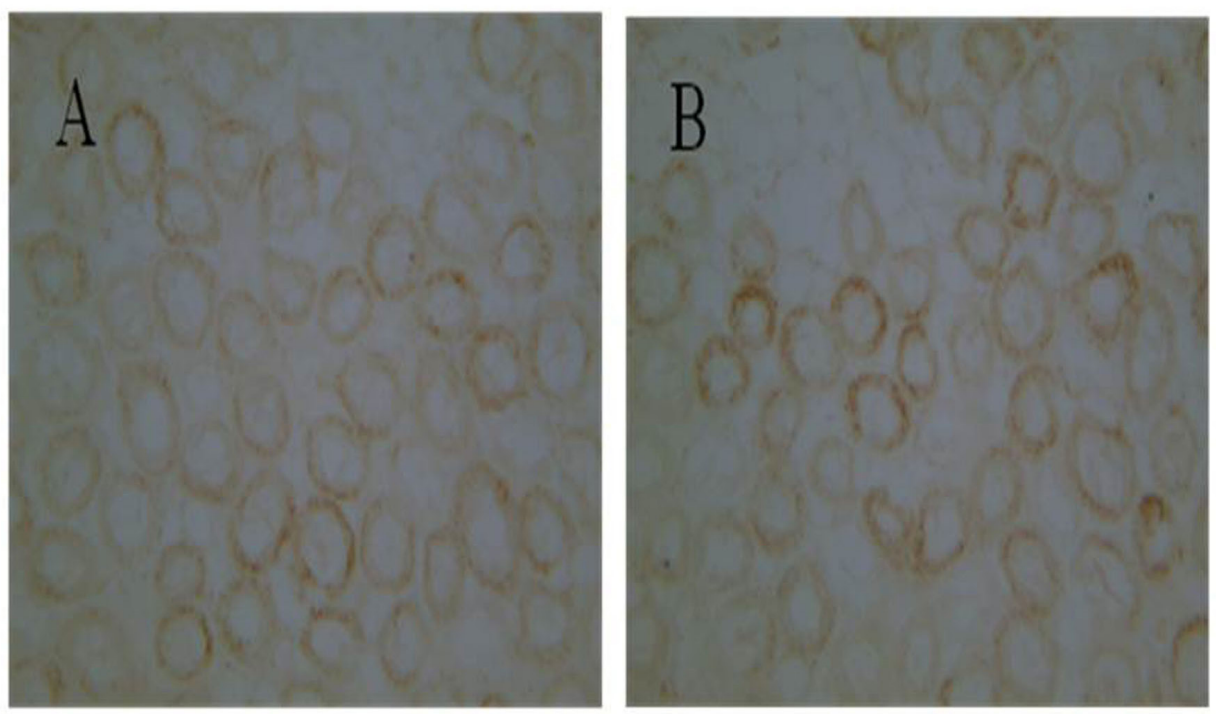

Figure 6. Immunohistochemical staining of ACE2 in kidney. Section from Control group rats, A is 400X; section from Experiment group, B is 400X.

\section{DISCUSSION}

STZ was first developed as an antibiotic. HouhuaFang et al. (2002) reported that this drug promotes the development of hyperglycemia. Presently, the method of STZ-induced hyperglycemia is widely used in various scientific fields. YafeiShen and YanchenXu (2005). established a rat model of hyperglycemia and renal injury by injecting STZ intraperitoneally into rats. Experimental evidence showed that blood sugar levels increased $(>16.7 \mathrm{mM})$ in rats that received an STZ injection as compared to uninjected rats and that this increase was accompanied by polydipsia, polyphagia, polyuria, and emaciation symptoms. Experiments to test renal function showed that the content of urinary protein, urinary creatinine, and urea nitrogen were also markedly increased in rats that received an STZ injection. Renal histopathology showed glomerular hypertrophy, diffuse mesangial broadening, arteriolar endothelial thickening, the distribution of plaques, and the shedding of renal tubular epithelial cells at sites of serious lesions. Therefore, the biochemical index of renal function and histology fully demonstrate that STZ causes serious damage to the kidneys of these rats.

The kidney is one of the critical organs involved in the generation and cycling of RAS components. ACE is a core enzyme of RAS and its enzymatic product Ang II is the most im- 
portant effector of RAS. Ang II has an important role in regulating the pathological and physiological processes of the kidney. Ang II impacts the glomerular filtration rate by influencing the contractility of glomerular arteries in the renal tubule, thus regulating glomerular capillary internal pressure (Pratt, 1999; Mizuiri et al., 2008). Excessive Ang II expression may also cause changes to the filtration rate of the mesangial cells of the renal glomerulus by stimulating the contraction and the proliferation of mesangial cells, thus leading to glomerular injury and loss of long-term renal function (Tipnis et al., 2000; Guo et al., 2006; Ye et al., 2006). This is consistent with our results showing significantly higher Ang II protein levels in the plasma and renal tissue of rats with renal injury than in those of control rats, and suggests an important role for Ang II in causing renal injury in rats.

ACE2 is a recently discovered homologue of ACE. However, its effect on RAS is contrary to that of ACE. ACE2 efficiently catalyzes the conversion of Ang II into Ang-(1-7) causing the relaxation of blood vessels, the regulation of blood pressure, the reduction of cell proliferation, etc. (Fernandes et al., 2001; Ferrario 2006). Crackower et al. (2002) found that although Ace 2 knockout mice have normal blood pressure, they have increased levels of Ang II in their plasma and tissues, and show compromised function of the kidney, heart, and other tissues. Interestingly, double knockout mice lacking both the Ace and Ace 2 genes did not show a similar phenotype. These mice presented with normal levels of Ang II in plasma and tissue, thus suggesting that the tissue injury seen in the Ace 2 knockout mice may have been caused by an increase in Ang II levels in these mice. The functions of the 2 axes of RAS- the ACE2-Ang-(1-7) axis and the ACE-Ang II axis- are normally well balanced, with the ACE2Ang-(1-7) axis playing a role antagonistic to that of the ACE-Ang II axis. Furthermore, the balance between ACE2 and ACE activities determines the levels of Ang II (Chappel and Ferrario 2006; Ingelfinger, 2006). By studying 24 week old rats with diabetic nephropathy, Tikellis et al. (2003) found that a 30\% drop in the expression of ACE2 in the renal tubules caused an increase in tissue Ang II expression and renal tubulointerstitial fibrosis. In this study, by studying 4 week old rats with STZ-induced diabetic renal disease, we found that the amount of circulatory and tissue Ang II significantly increased in rats with renal damage as compared to control rats. Ace 2 and Ace mRNA levels in the kidney also increased significantly, with Ace mRNA levels showing a greater increase than Ace 2 mRNA levels. Several factors can influence and regulate Ace/Ace 2 gene and protein expression in an in vitro and in vivo environment. We speculate that the ratio of Ace 2 to Ace mRNA is regulated through a compensatory mechanism in rats. In the etiology of kidney injury, ACE2 and ACE may both be activated. Although the 2 proteins are antagonistic, an imbalance between ACE and ACE2 levels may cause an imbalance in RAS, leading to the accumulation of Ang II and eventually to renal tissue injury. However, further experiments will be required to determine the precise mechanism of action.

In this study, we also assayed the levels of Mas receptor mRNA, plasma Ang-(1-7), At1 mRNA, and plasma and renal Ang II. The results showed that Ang II levels in plasma and renal tissue were significantly higher in STZ-treated vs control rats. However, although At1 mRNA levels showed an increasing trend and Mas receptor mRNA levels showed a decreasing trend in STZ-treated $v s$ control rats, these differences were not statistically significant. This suggests that the ACE-Ang II-AT1 pathway may be more active than the ACE2-Ang-(1-7)-Mas pathway. We believe that this imbalance between the ACE-Ang II-AT1 axis and the ACE2Ang-(1-7)-Mas axis is an important factor in the observed renal injury. Excessive activation of the ACE-Ang II-AT1 pathway may accelerate the production of Ang II. Furthermore, lower 
activity of the ACE2-Ang-(1-7)-Mas axis may also reduce Ang II degradation and Ang-(1-7) generation, leading to the accumulation of Ang II, which could eventually cause tissue injury. Recently, Vijay et al. (2008) showed that in rat renal tubular epithelial cells cultured in vitro Ang II $(1 \mu \mathrm{M})$ could significantly increase $A C E$ mRNA/protein expression and decrease $A C E 2$ mRNA/protein expression through the AT1-ERK/p38 MAP pathway. The excessive accumulation of Ang II may also affect Ace2 expression through feedback inhibition.

In conclusion, our results show that, upon severe kidney injury, glomerular RAS is activated, circulating and tissue Ang II levels increase, and Ace 2 and Ace mRNA levels increase. The greater increase in Ace mRNA levels as opposed to Ace 2 mRNA levels suggests that the activity of the ACE-Ang II-AT1 pathway is higher than that of the ACE2-Ang-(1-7)-Mas pathway. However, further study is warranted to understand the mechanism underlying this increase.

\section{ACKNOWLEDGMENTS} A200850).

Research supported by the National Natural Science Foundation of China (\#30871838

\section{REFERENCES}

Chappel MC and Ferrario CM (2006). ACE and ACE2: their role to balance the expression of angiotensin II and angiotensin-(1-7). Kidney Int. 70: 8-10.

Crackower MA, Sarao R, Oudit GY, Yagil C, et al. (2002). Angiotensin-converting enzyme 2 is an essential regulator of heart function. Nature 417: 822-828.

Donoghue M, Hsieh F, Baronas E, Godbout K, et al. (2000). A novel angiotensin-converting enzyme-related carboxypeptidase (ACE2) converts angiotensin I to angiotensin 1-9. Circ. Res. 87: E1-E9.

Fernandes L, Fortes ZB, Nigro D, Tostes RC, et al. (2001). Potentiation of bradykinin by angiotensin-(1-7) on arterioles of spontaneously hypertensive rats studied in vivo. Hypertension 37: 703-709.

Ferrario CM (2006). Angiotensin-converting enzyme 2 and angiotensin-(1-7): an evolving story in cardiovascular regulation. Hypertension 47: 515-521.

Guo RW, Yang LX, Li MQ, Liu B, et al. (2006). Angiotensin II induces NF-kappa B activation in HUVEC via the p38MAPK pathway. Peptides 27: 3269-3275.

HouhuaFang (2002). Medical Experimental Animal Models. Military medical science press, Beijing.

Ingelfinger JR (2006). ACE2: a new target for prevention of diabetic nephropathy? J. Am. Soc. Nephrol. 17: 2957-2959.

Koka V, Huang XR, Chung AC, Wang W, et al. (2008). Angiotensin II up-regulates angiotensin I-converting enzyme (ACE), but down-regulates ACE2 via the AT1-ERK/p38 MAP kinase pathway. Am. J. Pathol. 172: 1174-1183.

Mizuiri S, Hemmi H, Arita M, Ohashi Y, et al. (2008). Expression of ACE and ACE2 in individuals with diabetic kidney disease and healthy controls. Am. J. Kidney Dis. 51: 613-623.

Pratt RE (1999). Angiotensin II and the control of cardiovascular structure. J. Am. Soc. Nephrol. 10 (Suppl 11): S120-S128.

Santos RA, Ferreira AJ and Simoes e Silva AC (2008). Recent advances in the angiotensin-converting enzyme 2-angiotensin(1-7)-Mas axis. Exp. Physiol. 93: 519-527.

Tikellis C, Johnston CI, Forbes JM, Burns WC, et al. (2003). Characterization of renal angiotensin-converting enzyme 2 in diabetic nephropathy. Hypertension 41: 392-397.

Tipnis SR, Hooper NM, Hyde R, Karran E, et al. (2000). A human homolog of angiotensin-converting enzyme. Cloning and functional expression as a captopril-insensitive carboxypeptidase. J. Biol. Chem. 275: 33238-33243.

YafeiShen and YanchengXu (2005). Study on experimental diabetes animal model in rats induced by streptozotocin. Pract. Diagn. Ther. 19: 79-80.

Ye M, Wysocki J, Naaz P, Salabat MR, et al. (2004). Increased ACE 2 and decreased ACE protein in renal tubules from diabetic mice: a renoprotective combination? Hypertension 43: 1120-1125.

Ye M, Wysocki J, William J, Soler MJ, et al. (2006). Glomerular localization and expression of Angiotensin-converting enzyme 2 and Angiotensin-converting enzyme: implications for albuminuria in diabetes. J. Am. Soc. Nephrol. 17: 3067-3075. 